\title{
Diagnostic score for acute appendicitis: is it actually useful?
}

\author{
Viroj Wiwanitkit
}

Received: 31 May 2010 / Accepted: 10 June 2010/Published online: 26 June 2010

(C) Springer-Verlag 2010

\section{Dear Editor,}

I read a recent report by Lintula et al. with great interest [1]. Lintula et al. concluded that "The use of the acute appendicitis score developed for paediatric patients seems to provide some benefits compared to an unaided clinical diagnosis and may, thus, be a useful diagnostic tool for general surgeons [1]." There are some concerns on the Lintula score in this report. First, it is still questionable if this score is user-friendly. Many steps in scoring might be difficult to perform or process. Second, the diagnostic property of using the Lintula score is not statistically different than a naïve approach. This might not support that there is additional clinical usefulness in using a complicated scoring system. In addition, the lower sensitivity means a higher false-positive. This might lead to negative appendectomy and can lead to the situation of wrong management [2].

\section{References}

1. Lintula H, Kokki H, Pulkkinen J, Kettunen R, Gröhn O, Eskelinen M (2010) Diagnostic score in acute appendicitis. Validation of a diagnostic score (Lintula score) for adults with suspected appendicitis. Langenbecks Arch Surg (in press)

2. Wiwanitkit V (1999) Appendectomies that almost went wrong. J Med Assoc Thai 82(12):1273-1274

V. Wiwanitkit $(\bowtie)$

Bangkhae, Bangkok, Thailand 10160

e-mail: wviroj@yahoo.com 